\title{
Quantitative risk assessment of hemolytic uremic syndrome associated with consumption of bulk milk sold directly from producer to consumer in South Africa
}

Ntuli, Victor; Njage, Patrick Murigu Kamau; Bonilauri, Paolo; Serraino, Andrea; Buys, Elna M.

Published in:

Journal of Food Protection

Link to article, DOI:

10.4315/0362-028X.JFP-17-199

Publication date:

2018

Document Version

Peer reviewed version

Link back to DTU Orbit

Citation (APA):

Ntuli, V., Njage, P. M. K., Bonilauri, P., Serraino, A., \& Buys, E. M. (2018). Quantitative risk assessment of hemolytic uremic syndrome associated with consumption of bulk milk sold directly from producer to consumer in South Africa. Journal of Food Protection, 81(3), 472-481. https://doi.org/10.4315/0362-028X.JFP-17-199

\section{General rights}

Copyright and moral rights for the publications made accessible in the public portal are retained by the authors and/or other copyright owners and it is a condition of accessing publications that users recognise and abide by the legal requirements associated with these rights.

- Users may download and print one copy of any publication from the public portal for the purpose of private study or research.

- You may not further distribute the material or use it for any profit-making activity or commercial gain

- You may freely distribute the URL identifying the publication in the public portal 
Running title: Quantitative risk assessment of hemolytic uremic syndrome associated with consuming bulk milk.

Quantitative risk assessment of hemolytic uremic syndrome associated with consumption of bulk milk sold directly from producer to consumer in South Africa

\section{Victor Ntuli ${ }^{1}$, Patrick M.K Njage ${ }^{1,2}$, Paolo Bonilauri ${ }^{3}$, Andrea Serraino ${ }^{4}$, Elna M. Buys ${ }^{1 *}$}

${ }^{1}$ Department of Food Science, University of Pretoria, Private Bag X20, Hatfield, Pretoria 0028, South Africa.

${ }^{2}$ Division for Epidemiology and Microbial Genomics, National Food Institute, Technical University of Denmark, Kongens Lyngby, Denmark.

${ }^{3}$ Experimental Institute for Zooprophylaxis in Lombardy and Emilia Romagna, Via Bianchi 7/9, 25124 Brescia, Italy.

${ }^{4}$ Department of Veterinary Medical Sciences, University of Bologna, Via Tolara di Sopra 50, 40064 Ozzano Emilia, Bologna, Italy.

Key words: Milk, Shigatoxin, E. coli, Risk, Modelling

\footnotetext{
* Author for correspondence: Tel: (+27) 12 4203209; Fax: (+27) 12 4202839; E-mail: elna.buys@up.ac.za
} 


\begin{abstract}
This study was envisaged to estimate the hemolytic uremic syndrome (HUS) risk associated with consumption of shigatoxin producing E.coli (STEC) contaminated producerdistributor bulk milk (PDBM) in South Africa. Data was obtained from recently completed studies in South Africa taking into account prior collected prevalence data of STEC in raw and pasteurized PDBM, and survey information from producer-distributor (PD) outlets and households. Inputs for the models were complemented with data from published and unpublished literature. A probabilistic exposure model was developed with Monte Carlo simulation in Excel add-in software using @Risk software. Hazard characterization was based on an exponential dose-response model to calculate the probability of illness from STEC in age groups below and above 5 years. Mean estimated STEC concentration was $0.12 \mathrm{CFU} / \mathrm{ml}(95 \% \mathrm{CI}: 0-1.2 ; \sigma=$ 0.34), for raw PDBM and 0.08 CFU /ml (95\% CI: $0-1 ; \sigma=0.27)$, for pasteurized PDBM. A higher risk of HUS cases per-year was recorded in raw than pasteurized PDBM and also in age groups below 5 years. For every 100000 PDBM portions consumed, the expected median number of HUS cases per-year were 52 and 3.2 for age groups under 5 years and above 5 years in raw PDBM, respectively. The median cases per-year attributable to pasteurized PDBM were 47 and 2.9 for age groups under 5 years and above 5 years, respectively. Sensitivity analysis revealed that serving volume and time taken to sell PDBM at PD outlets as factors with the greatest impact on probability of illness. The models developed in this study are an example of risk assessments for milk produced and marketed from similar scenarios across the globe.
\end{abstract}


Over the years, shigatoxin producing Escherichia coli (STEC) have globally evolved from clinical novelty to primary food safety and public health concern (28). Shigatoxin producing $E$. coli pathotypes exhibit different clinical syndromes with distinctive pathological and epidemiological characteristics of disease $(8,48)$. Long-term sequelae of STEC infection is the serious complication known as hemolytic uremic syndrome (HUS). Albeit the development of HUS in individuals who have been infected by STEC being dependent on host susceptibility (immune status and immunity imparted by previous exposure) and dose ingested, the most vulnerable members are children under 5 years, the elderly and immune-compromised individuals. However, some STEC strains (O104 and O157 serotypes) have been proven to cause HUS even in healthy adults (34). Studies have shown that a few STEC cells are necessary to cause illness. Ingestion of $5-50$ cells of STEC can cause HUS to humans $(8,12,13,42)$.

Shigatoxin producing E. coli $\mathrm{O} 157: \mathrm{H} 7$ is still recognized as epidemiologically significant world-wide, however, in some geographical regions, non-O157 STEC (O26, O103, O111 and O145) are becoming prominent as important E. coli pathotypes $(13,28)$. Recent reports on raw and pasteurized PDBM in South Africa (SA) indicated prevalence of STEC O157 and non-O157 ranging from $10-54 \%(5,36,44,45)$. Ntuli et al. (45) documented emerging non-O157 STEC O2, O9, O20, O43, O64, O68, O83, O112, O155 and O157 in PDBM in SA.

Documented milkborne disease outbreaks have been linked to consumption of both raw $(6,7,14)$ and pasteurized (23) bulk milk contaminated with STEC, in particular O157. The European Food Safety Authority (EFSA) (16) documented 27 HUS cases in Europe (from 2007 -2012) attributed to STEC in bulk milk. In the USA, 13 HUS outbreaks associated with STEC in bulk milk were reported in 26 states during the period 2007 - 2012 (37). Reported cases of HUS linked to consumption of food in Africa are imprecise and the studies are few, although a 
recent review linked several outbreaks of STEC to food in the region (47). In SA, there are no official data existing on the incidence of HUS linked to STEC contaminated food. Although, several studies have isolated STEC from humans and livestock faeces, water and food $(1,26,41$, $45)$.

Studies carried out in SA on producer-distributor bulk milk (PDBM) revealed that the milk can be a potential public health threat as a result of E. coli pathotypes $(5,36,44,45)$. Producer-distributor (PD) bulk milk in SA is typically (i) raw milk sold at PD outlets for human consumption, (ii) milk that has been pasteurized at PD outlets and sold directly to consumers, and (iii) pasteurized milk that has been pasteurized elsewhere at an approved facility and sold at PD outlets. Producer-distributor bulk milk constitutes $2 \%$ of total milk produced and sold in SA. Only state certified PDs are permitted to sell raw milk directly to consumers according to the SA, 2001 Act (54), of 1972 (50). However, unregistered/unauthorised producers also find their way in the PDBM value chain. The sale of PDBM directly to consumers is a common practice in SA and around the world. In SA, no attempts have been made to quantify the risk posed to human health by pathogens in milk.

To gain an insight on the accurate estimates of the actual risk posed by consumption of PDBM contaminated by pathogenic E. coli, a quantitative microbial risk assessment modelling is one of the practice to evaluate food health risks and control $(4,17)$. Using predictive modelling, several risk assessment studies have been conducted in the USA, Europe and Africa to estimate disease cases due to milk borne pathogens, $(9,19,20,24,29)$. The estimates of cases in the USA and Europe $(19,20,29)$ were in line with the epidemiological reports from the respective countries. 
Owing to the lack of epidemiological data, the burden of pathogenic E. coli linked to consumption of PDBM in SA has not been assessed. Given that the prominent complication of gastrointestinal STEC infections in humans is HUS, this study was envisaged to estimate the HUS risk associated with consumption of STEC contaminated PDBM under the current production and marketing conditions in SA. This will enable assessment of factors that would have the greatest impact on public health and safety along the PDBM supply chain as well as formulating hypothetical mitigation strategies. Furthermore, this risk analysis facilitated the identification of data scarcity, which needs to be addressed for future quantitative risk assessments on PDBM. The models developed in this study are an example for other risk assessments in milk produced and marketed from similar scenarios across the globe.

\section{MATERIALS AND METHODS}

Field survey. A survey was conducted in urban and peri-urban parts of Pretoria in SA (one of the PDBM sampling areas) with the aim of getting an insight on the typical flow of PDBM from outlets to consumer and PDBM consumption patterns. Because Pretoria can represent SA in terms of PDBM consumer behavior and consumption patterns, socioeconomic status of consumers, registered/unregistered PDs, it was an ideal area for collecting data to assess the risk of STEC in PDBM. Furthermore, Pretoria has one of the highest number of PDs in SA (44). A questionnaire was developed to capture the following information; (i) average volumes of PDBM produced or received at outlets per-day (ii) PDBM handling practices and storage conditions at outlets, (iii) average volumes of PDBM sold per-day (iv) PDBM handling practices during transportation to home, (v) consumer handling practices and storage conditions, and also consumption patterns. Milk consumption in households also included identification of consumers' age. A total of 15 PDBM outlet operators were interviewed in the survey and in 
households, 80 respondents provided data for 300 consumers (i.e. age groups $0-5$ and above 5 years). The data was analyzed using SPSS Statistics 21. To test for significant difference between age groups, $0-5$ and above 5 years, in frequency and volume of consumption, analysis of variance and the post hoc Bonferroni tests were performed on normally distributed variables with equal variances. We also applied the Kruskal-Wallis tests for non-normally distributed variables. Information obtained from the survey was used as input for the models.

\section{Overview of PDBM pathway to consumer and exposure model. Consumers of PDBM}

obtain their milk from different sources either as raw or pasteurized. Stages prior PD outlets were not included in this model (i.e. from the farm to PD outlets). The model was developed starting from PD outlets to household level for PDBM which was sold either as raw or pasteurized. A "modular process risk" framework (40) was adopted to simulate the scenario which the milk undergoes from the PD outlets to consumption. The same scenario was used for either raw or pasteurized PDBM, however, what differed was the STEC prevalence and concentration in raw and pasteurized PDBM at the time of sell at PD outlets (44). Consumers either bring their own containers to buy PDBM or buy pre-filled small plastic containers ( 1 to $5 \mathrm{~L}$ ). We modelled changes in prevalence and concentration of STEC in PDBM from outlets to consumption after storage at home. At each step, basic microbial and milk handling processes, such as growth and partitioning were identified and applied. Partitioning is when a major unit (bulk milk) is split up into several minor units (small retail volumes). We divided the model into the following steps: (i) PD storage (ii) transport time and temperature from PD to home and consumer handling (iii) consumption habits at home and exposure to STEC per-serving. Each step, in sequence, produced one or more output distributions that served either as inputs to the next step or as final outputs of the estimation of the probability and concentration in a single serving at consumption. 
The model was developed from input data derived from the field survey, a completed study on PDBM by Ntuli et al. (44), other published literature and expert opinion whenever possible. Input parameter variables, their description and associated equations or distributions, for PDBM production model are presented in Table 1. The same model was used for both raw and pasteurized PDBM.

Estimation of STEC concentration in PDBM. Data on the prevalence of STEC in raw and pasteurized PDBM samples, from all the provinces in SA, reported in previous studies by Ntuli et al. $(44,45)$ were incorporated in the estimation of STEC concentration. The studies reported STEC prevalence of 11.0 and $7.7 \%$ in raw and pasteurized PDBM samples from all the provinces in SA, respectively. Shigatoxin producing E. coli in the positive samples ranged from 1 to $3 \mathrm{CFU} / \mathrm{ml}$. We used a Poisson distribution to calculate the mean concentration of STEC in both raw and pasteurized PDBM (51). To test that STEC in PDBM follow a Poisson distribution we carried out a Chi-square goodness of fit test.

Producer-distributor storage. The distribution of PDBM volumes produced or received per-day at outlets were estimated from a study by Caine et al. (5) and from the survey (Table 1). Milk is stored as either raw or pasteurized and the volumes of PDBM was incorporated in the model as a distribution representing variability in milk volumes at each outlet. We used uniform distributions to simulate variability in storage temperatures and time taken to sell all the milk from one batch and this was used in the growth model (Table 1). Cross contamination at PD storage is uncertain due to lack of data or published data, therefore, we assumed no cross contamination during modelling. Maximum population density (MPD) and maximum growth rate ( $\mu$ max) of STEC at $9.5^{\circ} \mathrm{C}$ in milk used in the growth model was obtained from a study by Kauppi et al. (27). Assuming no lag time in the growth kinetics, concentration after growth 
TABLE 1: Input parameters for exposure model of STEC in raw and pasteurized producer-distributor bulk milk: Description, equations or distribution, values and units of the input parameters and data sources.

Steps

Parameter Description

Distribution/ Equation/values

Units

Data Source/reference

Producer-distributor $\mathrm{IP}_{\mathrm{PDS}}$

storage

$\mathrm{IC}_{\text {PDS }}$
$\mathrm{V}_{\text {outlet }}$
Temp $_{\text {PDS }}$
Time $_{\text {PDS }}$
Milk $_{\text {sale/day }}$
G $_{\text {Conc }}$

Conc $_{\mathrm{PDS}}$

Size $_{\text {PDS }}$
Initial prevalence of STEC 11 raw milk

positive PDBM

Initial concentration of

STEC in PDBM samples

Volume produced or

received at outlets.

PDBM storage temperature RiskUniform $(8,11)$

Time taken to sell PDBM RiskUniform $(24,48)$

Average PDBM sale per- RiskUniform(500000, 5000000)

day

Growth of STEC during

PDBM storage

Concentration of STEC

after growth occurs during

storage of PDBM

Volume of milk sold to

consumer and size of

containers
0.12 raw milk

0.08 pasteurized milk

RiskPert(500000, 1000000,5000000)

Time $_{\text {PDS }}$ in $\mathrm{hr} \mathrm{x} \mu \max$

Where: $\mu \max =0.036$

$\mathrm{IF}\left(\mathrm{IC}_{\mathrm{PDS}} \times 10^{\mathrm{G}}\right)>\mathrm{MPD}, \mathrm{MPD},\left(\mathrm{IC}_{\mathrm{PDS}} \times 10^{\mathrm{G}}\right)$

Where:

$\mathrm{MPD}=31622777$

RiskPert(500,1000,5000)
44

$\%$

$\mathrm{CFU} / \mathrm{ml}$

$\mathrm{ml}$

5

Survey

${ }^{\circ} \mathrm{C}$

This study

h This study

ml This study

Log CFU

Log CFU/h 27

$\mathrm{CFU} / \mathrm{ml}$

$\mathrm{CFU} / \mathrm{ml}$

$\mathrm{ml}$

This study 


\section{Prev $_{\text {consumer }}$ \\ $\mathrm{C}_{\text {consumer }}$}

Transport time and

temperature from

producer-distributor Trans Time $_{\text {Tim }}$

to home

and Consumer

handling

Time $_{\text {shelflife }}$

Temp fridge $_{\text {f }}$

G1

$\mathrm{C}_{\mathrm{HST}}$

Consumption habits

Serving $_{\text {size }}$

at home and

exposure to STEC

per-serving
New PDBM sample prevalence with STEC after packaging into smaller units

New PDBM STEC

concentration after

packaging into smaller

units

Transportation temperature

Transportation time

RiskPert(14.3, 26, 38)

RiskUniform $(0.5,3)$

${ }^{\circ} \mathrm{C}$

Time until all PDBM is consumed at home

Temperature refrigeration at home

$\{0.39,0.04,0.04,0.01\})$

Growth of STEC in PDBM during refrigeration storage at home

Time $_{\text {shelflife }}$ in hr x $\mu$ max

Where:

$\mu \max =$

RiskCumulD(0.019,0.041,\{0.019,0.028,0.036,0.041\} Log CFU/h

$\{0.39,0.04,0.04,0.01\})$

Concentration STEC in

PDBM after growth occurs

during refrigeration storage

at home

Milk serving size at

consumer level

RiskPert $(150,500,1000)$

$\mathrm{ml}$

This study

Generation time of STEC

under refrigeration

RiskTriangle(34.2, 45.1, 56)

$\mathrm{h}$

22
$\mathrm{CFU} / \mathrm{ml}$

This study

This study

This study

$\log \mathrm{CFU}$

conditions 


\begin{tabular}{|c|c|c|c|c|}
\hline Time $_{\text {shelflife }}$ & $\begin{array}{l}\text { Time milk is stored and } \\
\text { consumed at home }\end{array}$ & RiskPert $(24,48,120)$ & $\mathrm{h}$ & This study \\
\hline $\mathrm{B}_{\mathrm{EX}}$ & $\begin{array}{l}\text { Consumer habits (milk } \\
\text { boiling before consumption } \\
\text { at home) }\end{array}$ & RiskBernoulli(0.67) x $D_{\mathrm{EX}}$ & & \\
\hline $\mathrm{D}_{\mathrm{EX}}$ & $\begin{array}{l}\text { Log reduction of those who } \\
\text { insufficient heat the milk at } \\
\text { consumer level }\end{array}$ & RiskTriangle $(2,4,6)$ & $\begin{array}{l}\mathrm{Log} \\
\mathrm{CFU} / \mathrm{ml}\end{array}$ & 21 \\
\hline Dose $_{\text {per-serving }}$ & Dose of STEC per-serving & $\begin{array}{l}10^{\wedge}\left(\log \left[10^{\mathrm{CHST}} \times 2^{\wedge(\text { Timeshelflife } / \text { TimeGT-EX })}\right]-B_{\mathrm{EX}}\right) \mathrm{x} \\
\text { Serving }\end{array}$ & $\mathrm{CFU}$ & 21 \\
\hline
\end{tabular}


occurs during storage was computed taking into account, MPD, $\mu$ max, time all the milk is sold and the initial concentration (Table 1). Prevalence after growth occurs was considered unaffected.

Consumers buy PDBM in plastic containers or the milk is packaged into retail units $(0.5$ to $5 \mathrm{~L}$ ) at PD outlets. The model used to calculate STEC prevalence and concentration in smaller units assumed that STEC is randomly distributed in the milk. The new prevalence is the probability that at least one STEC cell is present in the new smaller units, given that the bulk milk where it is drawn was previously contaminated with STEC, was considered equal to the fraction of bulk milk that the small unit represents. Therefore, STEC prevalence in the containers is adjusted by the probability that one or more STEC cells will end up in a random smaller unit. Concentration of STEC after packaging into smaller volumes was calculated by binomial sampling of the number of STEC cells that are in the small units. Therefore, the new STEC concentration is randomly generated as, contamination count divided by the small unit volume (Table 1) (43). A uniform distribution was used to model the distribution of milk volumes sold per-day and this was used to calculate number of servings consumed per-day.

Transport from PD to home and consumer handling. Based on the survey, we assumed that there was negligible or no STEC growth during transportation of PDBM, given short distances and time from outlets to home, even though the milk was transported at abused temperatures (Table 1). However, time taken to transport the milk from PD to home and storage at home was treated as a continuum during calculation for STEC growth after refrigeration at home. On the basis of the survey, milk was consumed up to 5 days especially when refrigerated. Hudson and Hartwell (25) and Marklinder et al. (32) noted that there is variability in refrigeration temperatures in homes that can allow E. coli growth in food. These authors 
observed that $39 \%$ of households refrigerated their food at $6-7^{\circ} \mathrm{C}, 4 \%$ at $7-8^{\circ} \mathrm{C}, 4 \%$ at $9-$ $10^{\circ} \mathrm{C}$ and $1 \%$ at $12^{\circ} \mathrm{C}$. We used a cumulative distribution of the different refrigeration temperatures from different proportions of consumer as an input for the growth model at home storage. Assuming no lag time in the growth kinetics, growth was further computed taking into account; STEC concentration after packaging into smaller units, maximum growth rate, distributions representing variability of time taken to transport the milk from PD to home and storage at home, and MPD of STEC in milk at refrigeration temperatures (27). Maximum growth rate $(\mu \max )$ of STEC at refrigeration temperatures was derived from a cumulative distribution of the different $\mu$ max values at $6-7,7-8,9-10,12^{\circ} \mathrm{C}$ and proportions of consumers storing milk under the respective different refrigeration temperatures $(25,32)$. Prevalence after growth during storage at home in refrigerators was considered unaffected (Table 1).

Consumption habits at home and exposure to STEC per-serving. According to the survey, $67 \%$ of the consumers boiled both raw and pasteurized PDBM before consumption. Giacometti et al. (22) observed that boiling milk eliminates viable E. coli cells. However, the remaining $33 \%$ used methods such as warming the milk using a microwave, mixing with hot tea or porridge, which we consider as inadequate/insufficient heat treatment of milk. Log reduction for the insufficient heat treatment of milk was modelled using a triangular distribution (21) (Table 1). Consumer habits was used in the final exposure model. The distribution of PDBM serving size was characterised by values from the survey (Table 1). Final exposure (concentration) of STEC per-serving was calculated as an output using the model in Table 1.

Dose response. We adopted the dose response model of STEC in food used by Delignette-Muller et al. (13). The authors directly modelled the probability of HUS as a function 
TABLE 2: Dose response assessment for STEC in raw and pasteurized producer-distributor bulk milk: Description, equations or distribution, values and units of the input parameters and data sources.

\begin{tabular}{|c|c|c|c|c|}
\hline Parameter & Description & Distribution/ Equation/values & Units & Data Source/reference \\
\hline$\overline{P_{\text {HUS }}}$ & $\begin{array}{l}\text { Probability of hemolytic } \\
\text { uremic syndrome }\end{array}$ & $\begin{array}{l}\mathrm{P}_{\mathrm{HUS}}=1-(1-r)^{D} \\
\text { Where: } \\
r \text { is the dose response parameter per-organism: } \mathrm{r}= \\
1.28 \times 10^{-3}(0 \text { to } 5 \text { years }) \\
\quad \mathrm{r}=2.4 \times 10^{-4} \quad(>5 \text { years }) \\
D \text { is dose per-serving (Dose } \text { per-serving })\end{array}$ & $\mathrm{CFU}$ & 49 \\
\hline$P_{\text {Serving }}$ & $\begin{array}{l}\text { Probability of illness per- } \\
\text { serving }\end{array}$ & $\mathrm{P}_{\text {Serving }}=\mathrm{P}_{\text {HUS }}$ & & 29 \\
\hline \multirow[t]{6}{*}{$\mathrm{N}_{\text {case }}$} & $\begin{array}{l}\text { Number of hemolytic uremic } \\
\text { syndrome cases per-year }\end{array}$ & $\mathrm{P}_{\text {Serving }} \mathrm{x}$ Number of servings per-year & & 29 \\
\hline & & $\begin{array}{l}\text { Where: } \\
\text { Number of servings per-year }=\text { frequency of } \\
\text { consumption per-month for each age group } x \\
\text { portions consumer with insufficient heat treatment. }\end{array}$ & & \\
\hline & & $\begin{array}{l}\text { Frequency of consumption per-month for each age } \\
\text { group: } \\
(0 \text { to } 5)=\operatorname{RiskUniform}(16,30) \\
>5 \text { years }=\operatorname{RiskPert}(0,8,16)\end{array}$ & & This study \\
\hline & & $\begin{array}{l}\text { Portions with insufficient heat treatment }= \\
0.33 \text { x portions consumed per-year } \\
\text { Where: } 0.33 \text { is proportion of consumers who } \\
\text { insufficiently heat the milk }\end{array}$ & & This study \\
\hline & & $\begin{array}{l}\text { Portions consumed per-year }=\left(\left(\text { Milk }_{\text {sale/day }} \times 178\right) /\right. \\
\left.\text { Size }_{\text {PDS }}\right) \text { x } 365 \text { days } \\
\text { Where: } 178 \text { is number of PDs in SA }\end{array}$ & & \\
\hline & & & & 44,45 \\
\hline
\end{tabular}


of ingested dose. Probability of illness from STEC infections is dependent on age and other factors as reported by Nauta et al. (39). In the current study, we used two dose-response models for two age groups, $0-5$ and $>5$ years (Table 2). Children under 5 years are more susceptible to STEC as documented from an epidemiological study (31). The values for $r$ used in the model were estimated by Delignette-Muller et al. (13) for each age group (Table 2). Using an exponential dose model, the probability of HUS per-serving was computed by combining the dose estimate and contamination prevalence (49). Number of cases per-year was calculated by multiplying the probability of HUS per-serving and the number of serving per-year for each target age group (Table 2).

Simulation and analysis. Stochastic modelling of the exposure with STEC for all scenarios were implemented with the Monte Carlo simulation technique by using the risk analysis software @Risk 7.5 (Palisade Corporation, Ithaca, USA). All models were simulated for 100000 iteration as carried out by Latorre et al. (29) and Giacometti et al. (21). The outputs of the model was the median risk of HUS per-serving in each class of consumers' ages. Sensitivity analysis for each scenario was performed to identify important parameters from their corresponding distributions. Spearman's correlation coefficient was used to estimate the impact of PDBM value chain practices on the variability in exposure with STEC in PDBM per-year. We introduced possible PDBM handling scenarios to test the associated effects in reducing exposure per-serving to STEC to consumers who insufficiently heat the milk. These scenarios include: storage and handling of PDBM at $4{ }^{\circ} \mathrm{C}$ throughout the whole chain, time taken to sell the milk at PD outlets, time taken to consume all the milk at home and a combination of some of the PDBM handling practices. Storage and handling of PDBM at $4{ }^{\circ} \mathrm{C}$ throughout the whole chain was broken down into points where this storage effect was modelled (PD outlets, transportation to 
home and home refrigeration). We used 5, 6 and $7 \mathrm{~h}$ as time taken to sell the milk at PD outlets.

This is the possible and realistic time PDs can acquire milk and sell within the same day.

Maximum recommended time for raw milk storage at house hold is $72 \mathrm{~h} \mathrm{(21),} \mathrm{therefore,} \mathrm{we} \mathrm{used}$

12, 24 and $48 \mathrm{~h}$ as possible and realistic time taken to consume all the milk at home. A

combination of scenarios (storage at $4^{\circ} \mathrm{C}$ throughout the whole chain + time taken to sell the milk (5 h) + time taken to consume the milk (12 h)) was also evaluated.

\section{RESULTS}

There was high variability in data obtained from PD outlets and also from consumer handling and consumption of PDBM. Characteristics of data obtained from the survey are depicted in Table 3. Most PD outlet respondents $(60.0 \%, \mathrm{n}=15)$ reported that they received an average of $1000000 \mathrm{ml}$ of milk per consignment. Producer-distributors (90\%) specified that consumers of PDBM normally buy $2000 \mathrm{ml}$ each time. Storage temperatures, time taken to sell the milk and average volumes sold per day at PD outlets varied greatly (Table 3).

TABLE 3: Characterization of survey results obtained from interviews with producer-distributors and consumers of raw and pasteurized producer-distributor bulk milk.

\begin{tabular}{|c|c|c|c|c|}
\hline Variable & & Obs & Mean & SDV \\
\hline \multirow[t]{5}{*}{ Data from PD outlets } & Volume produced or received $(\mathrm{ml})$ & 15 & 1516665 & 839624 \\
\hline & Storage temperature $\left({ }^{\circ} \mathrm{C}\right)$ & 15 & 9.5 & 0.9 \\
\hline & Time taken to sell the milk (h) & 15 & 36 & 6.9 \\
\hline & Average milk sold per day $(\mathrm{ml})$ & 15 & 2749999 & 1299050 \\
\hline & Volume of milk sold to consumer (ml) & 15 & 1583 & 727 \\
\hline \multirow{3}{*}{$\begin{array}{l}\text { Consumer handling } \\
\text { practices and milk } \\
\text { consumption }\end{array}$} & Transportation to households (h) & 80 & 1.8 & 0.7 \\
\hline & Time to consume milk at households (h) & 80 & 55.9 & 17 \\
\hline & Milk serving size (ml) & 80 & 350 & 152 \\
\hline
\end{tabular}

Obs - Number of respondents, SDV - Standard deviation 
The interviewed respondents $(\mathrm{n}=80)$ provided data for 300 consumers of PDBM i.e. age groups $0-5(37.7 \%, \mathrm{n}=113)$ and above 5 years $(62.3 \%, \mathrm{n}=187)$. Majority $(80 \%, \mathrm{n}=80)$ of the consumers took an average of $0.5 \mathrm{~h}$ to transport the milk from PD outlets to home. Distances covered by consumers from PD outlets to home ranged between 500 to $5 \mathrm{~km}$ and most consumers $(40 \%, \mathrm{n}=80)$ who transported the furthest used cars. There was a significant difference noted between the young and adults both in frequency of consumption and consumption volume $(\mathrm{p}=0.001)$. The volume of $250 \mathrm{ml}$ was the most $(67 \%, \mathrm{n}=300)$ consumed and a daily frequency $(98 \%, \mathrm{n}=113)$, per-month, of consumption was the most indicated among the $0-5$ years. Most consumers $(77 \%, \mathrm{n}=187)$ above 5 years stated that they consume PDBM once per-week. Frequency of PDBM consumption for children under 5 years was 2.8 higher than population above 5 years. We factored in frequency of consumption to calculate the portions of milk consumed by the two age groups per-year (Table 2). Hence, from the calculations, the population under 5 years consumed 124984915 portions of milk per-year and the age group above 5 years consumes 43473014 portions per-year. Based on the survey, $67 \%$ $(n=80)$ of the consumers boiled both raw and pasteurized PDBM before consumption and the most stated time to consume all the milk after purchase was $48 \mathrm{~h}(54 \%, \mathrm{n}=80)$. All the consumers stored their milk in refrigerators at home.

Concentration of STEC in raw and pasteurized PDBM. From the prevalence data on STEC positive samples, the estimated number of STEC in raw $(0.12 \mathrm{CFU} / \mathrm{ml})$ and pasteurized (0.08 CFU/ml) PDBM was done by fitting a Poisson distribution. A Chi-square goodness of fit test was used to test the fit of the Poisson distribution. Pearson $\chi^{2}$ at 1.79 , degrees of freedom was 2 and $p$-value based on $\chi^{2}$ distribution was 0.20 for raw PDBM. For pasteurized PDBM, 
Pearson $\chi^{2}$ at 1.90 degrees of freedom was 1 and $p$-value based on $\chi^{2}$ distribution was 0.11 . Therefore, the Poisson distribution adequately predicted the estimated number of STEC in both PDBM types. The model gave a mean STEC estimate concentration of $0.12 \mathrm{CFU} / \mathrm{ml}$ (95\% CI: 0 $-1.2 ; \sigma=0.34)$, for raw PDBM and $0.08 \mathrm{CFU} / \mathrm{ml}(95 \% \mathrm{CI}: 0-1 ; \sigma=0.27)$, for pasteurized PDBM.

TABLE 4: Estimation of shigatoxin producing E. coli concentration per-serving in raw and pasteurized producerdistributor bulk milk.

\section{Parameter / percentile}

Estimated level of STEC (CFU/per-serving)

\begin{tabular}{ccc}
\hline & Raw PDBM & Pasteurized PDBM \\
\cline { 2 - 3 } Minimum & $3.2 \times 10^{-4}$ & $2.9 \times 10^{-4}$ \\
Mean & $4.1 \times 10^{2}$ & $3.7 \times 10^{2}$ \\
Maximum & $7.3 \times 10^{3}$ & $6.4 \times 10^{3}$ \\
$5^{\text {th }}$ & $5.8 \times 10^{-3}$ & $5.1 \times 10^{-3}$ \\
$50^{\text {th }}$ & 0.42 & 0.37 \\
$95^{\text {th }}$ & $1.9 \times 10^{3}$ & $1.7 \times 10^{3}$ \\
\hline
\end{tabular}

Exposure assessment. The estimated levels of STEC per-serving, after insufficient heating the milk, in both raw and pasteurized PDBM are depicted in Table 4. The quantity of STEC that a consumer was exposed to in a single serving of milk was a function of the initial concentration of STEC in PDBM at PD outlets, and the subsequent effects of handling and storage along the milk chain. Shigatoxin producing E. coli levels increased during storage at PD 
outlets and home refrigeration, reaching microbial loads of 42 (95\% CI: $15-569)$ CFU/perserving in raw and 28 (95\% CI: $10-385) \mathrm{CFU} /$ per-serving in pasteurized PDBM, prior heat treatment. Considering the $33 \%$ of consumers who insufficiently heat the milk before consumption, the STEC concentration per-serving ranged between $3.2 \times 10^{-4}$ and $7.3 \times 10^{3}$ CFU/per-serving for raw PDBM and $2.95 \times 10^{-4}$ to $6.42 \times 10^{3} \mathrm{CFU} /$ per-serving for pasteurized PDBM (Table 4). The model predicted prevalence of PDBM contaminated with STEC to be $11 \%$ and $8 \%$ for both raw and pasteurized PDBM at the time of consumption.

Risk characterization. To assess the risk posed to consumers from consuming STEC contaminated PDBM we used the exposure assessment model and each iteration predicted a probability of illness and consequently the number of HUS cases per-year (Table 5). In simulations where all consumers boil milk before consumption, no risk was calculated for both raw and pasteurized PDBM. The model estimated higher probability of illness per-serving for consumers of raw than pasteurized PDBM, when we considered consumer (both age groups) who insufficiently heat the milk before consumption. The highest median probability of illness per-serving was noted in children under 5 years for raw PDBM $\left(5.4 \times 10^{-4}\right)$, while consumers of pasteurized PDBM who are above 5 years of age recorded the least median probability $\left(9.0 \times 10^{-}\right.$ ${ }^{5}$ ) of illness pre-serving (Table 5). Number of HUS cases per-year were also higher for children under 5 years of age than consumers above 5 years of raw and pasteurized PDBM. For every 100 000 portions of PDBM, the highest recorded median number of HUS cases per-year (52) was observed in consumers below 5 years who consume raw PDBM (Table 5). The median cases per-year attributable to pasteurized PDBM were 47 and 2.9 for age groups under 5 years and above 5 years, respectively, for every 100000 pasteurized PDBM portions consumed. 
TABLE 5: Probability of illness per-serving and number of hemolytic-uremic syndrome cases per-year with consumption of raw and pasteurized producerdistributor bulk milk.

\begin{tabular}{|c|c|c|c|}
\hline Milk category & Population & $\begin{array}{l}\text { Probability of illness per-serving } \\
\text { Median }\left(5^{\text {th }}, 95^{\text {th }}\right) \text { percentiles }\end{array}$ & $\begin{array}{l}\text { Number of cases per-year } \\
\text { Median }\left(5^{\text {th }}, 95^{\text {th }}\right) \text { percentiles }\end{array}$ \\
\hline \multirow[b]{2}{*}{ Raw PDBM } & Under 5 years & $5.4 \times 10^{-4}\left(7.5 \times 10^{-6}, 0.91\right)$ & $52.0\left(0.68,1.3 \times 10^{5}\right)$ \\
\hline & Above 5 year & $1.0 \times 10^{-4}\left(1.4 \times 10^{-6}, 0.37\right)$ & $3.2\left(0.04,1.5 \times 10^{4}\right)$ \\
\hline \multirow{2}{*}{ Pasteurized PDBM } & Under 5 years & $4.8 \times 10^{-4}\left(6.7 \times 10^{-6}, 0.82\right)$ & $47.0\left(0.60,1.2 \times 10^{5}\right)$ \\
\hline & Above 5 year & $9.0 \times 10^{-5}\left(1.3 \times 10^{-6}, 0.33\right)$ & $2.9\left(0.03,1.3 \times 10^{4}\right)$ \\
\hline
\end{tabular}

Values are the median, $5^{\text {th }}$ and $95^{\text {th }}$ percentile obtained after 100000 iteration, using @ risk 7.5 in both raw and pasteurized PDBM

The values for number of cases were calculated for every 100000 portions of PDBM consumed. 
Effect of model parameters on the risk of HUS. In the current study, sensitivity analysis on the models indicated that serving volumes (Spearman's correlation coefficient $(\rho)=$ 0.17) had the greatest effect on the probability of HUS and the annual number of cases (Fig. 1). Time taken to sell the milk at PD outlets $(\rho=0.16)$ and PDBM storage time at home $(\rho=0.11)$ were also important factors that influenced probability of HUS and the annual number of cases. After packaging bulk milk into small containers for the consumer, the new modelled concentration of STEC $(\rho=0.06)$ also affected probability of illness. Insufficient heat treatment of PDBM before consumption, reduced the level of STEC and the subsequent risk of HUS in both raw and pasteurized PDBM $(\rho=-0.40)$ (Fig. 1). Reduced generation time of STEC during refrigeration at home, which is achieved by proper refrigeration, also reduced the risk of HUS ( $\rho$ $=-0.03)$

FIGURE 1: Sensitivity analysis between estimated probability of illness after one serving of producer-distributor bulk milk and important predictive factors along the value chain.

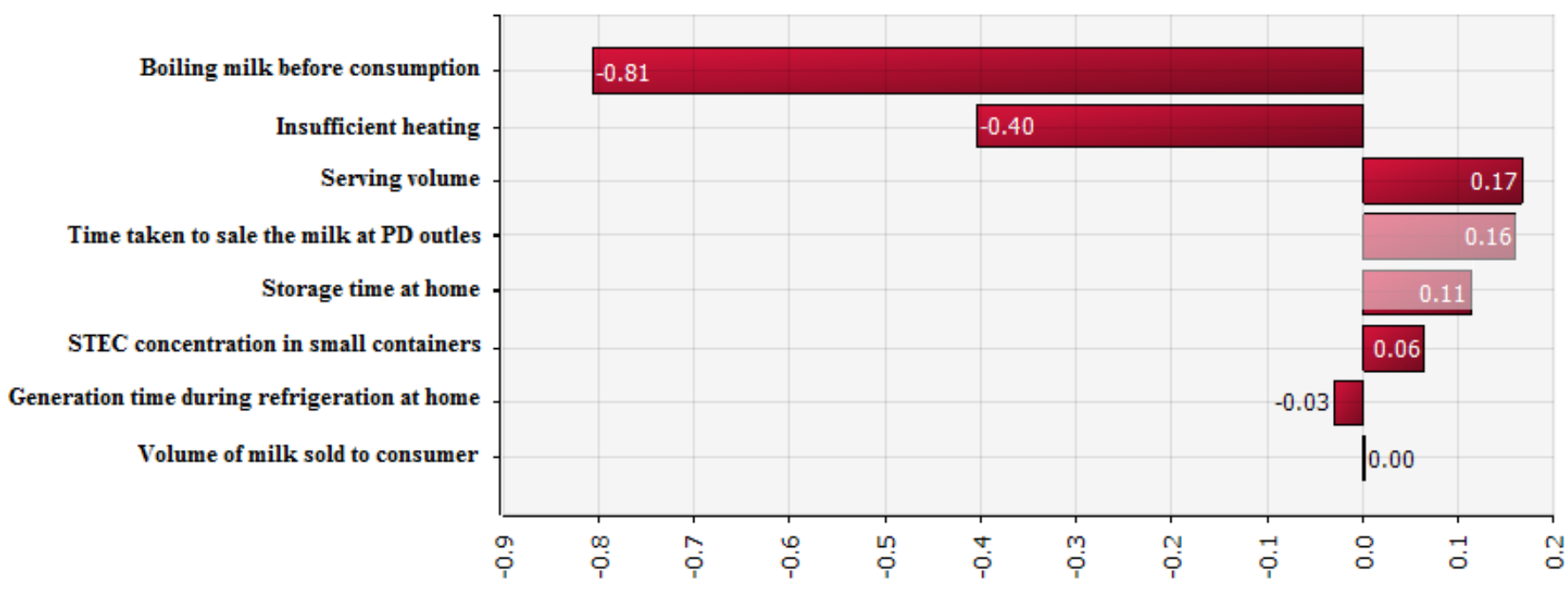

Coefficient Value 
TABLE 6: Possible handling scenarios and their associated effects in reducing exposure per-serving to shigatoxin producing E. coli to consumers who do not boil producer-distributor bulk milk.

\begin{tabular}{lcc}
\hline \multicolumn{1}{c}{ Handling procedures } & \multicolumn{1}{c}{$\begin{array}{c}\text { Reduction in concentration of STEC per-serving } \\
(\%)\end{array}$} \\
\hline & Raw PDBM & Pasteurized PDBM \\
\cline { 2 - 3 } & & 19.6 \\
Storage and handling at $4^{\circ} \mathrm{C}(\mathbf{a}):$ & 23.1 & 9.7 \\
$\quad$ PD outlets & 8.0 & 11.9 \\
$\quad$ Transportation home & 13.3 & 56.0 \\
$\quad$ Home refrigeration & & 54.3 \\
& & 45.1 \\
Time taken to sell the milk $(\mathbf{b}):$ & 54.2 & 57.8 \\
$5 \mathrm{~h}$ & 44.0 & 46.4 \\
$6 \mathrm{~h}$ & & 37.2 \\
$7 \mathrm{~h}$ & 55.8 & 88.5 \\
Time taken to consume all the milk at home $(\mathbf{c}):$ & 43.5 & 34.9 \\
$12 \mathrm{~h}$ & & \\
$24 \mathrm{~h}$ & 83.2 & \\
$48 \mathrm{~h}$ & & \\
$\mathbf{a}\left(4^{\circ} \mathrm{C}\right)+\mathbf{b}(5 \mathrm{~h})+\mathbf{c}(12 \mathrm{~h})$ & & \\
\hline
\end{tabular}

Possible PDBM handling scenarios. Storing PDBM at $4^{\circ} \mathrm{C}$ throughout the whole chain revealed that it was most effective when applied at PD outlets in both raw $(23.1 \%$ reduction of STEC concentration) and pasteurized (19.6\% reduction of STEC concentration) PDBM. We observed that, as time to sell PDBM and time to consume the milk after arriving at home reduced, the concentration of STEC per-serving also reduced significantly (Table 6). Reducing time taken to consume all the milk after arriving to $12 \mathrm{~h}$, was the most effective single handling practice, with 55.8 and $57.1 \%$ reduction in STEC concentration per-serving in raw and pasteurized PDBM, respectively. Considering time taken to sell the milk at PD outlets, the highest reduction in consumer exposure to STEC was observed when milk is received and sold to consumers within $5 \mathrm{~h}$ per-batch $(54.2$ and $56.0 \%$ reduction of STEC concentration in both raw and pasteurized PDBM respectively). Combining possible handling scenarios (storage at $4^{\circ} \mathrm{C}$ throughout the whole chain + time taken to sell the milk $(5 \mathrm{~h})+$ time taken to consume the milk 
(12 h)) was the most effective practice in reducing consumer exposure to STEC for both raw (83.2\% reduction of STEC concentration) and pasteurized (88.5\% reduction of STEC concentration) PDBM.

\section{DISCUSSION}

We carried out a stochastic quantitative microbial risk assessment, from PD outlets to consumption, of HUS associated with the consumption of STEC contaminated PDBM based on results from a study by Ntuli et al. $(44 ; 45)$ and also from a survey carried out in one of the sampling areas in SA. This provided an estimate of the nationwide PDBM scenario of HUS cases that may be linked to the consumption of STEC contaminated PDBM.

Estimated STEC concentration was lower in pasteurized $(0.08 \mathrm{CFU} / \mathrm{ml})$ than $\mathrm{raw}(0.12$ CFU/ml) PDBM. Under ideal conditions, no STEC cell survives pasteurization temperatures (23). Using a modelling approach, Clough et al. (9) highlighted that STEC contamination in pasteurized milk occurs either from inadequate pasteurization or post-pasteurization contamination. In their study, they reported that, although inadequate pasteurization may result in survival of STEC, subsequent dilution effects lowers probability of HUS risk associated with STEC to very low levels in packed milk.

Our model also assessed the risk introduced during consumer handling. This consist of steps after consumer purchase and the subsequent handling at household level. At these stages, PDBM is no longer controlled by professionals $(10,30,38)$. We treated temperature and time of milk handling and storage as independent parameters. This may have overestimated the risk of HUS since an implicit assumption, underlying the model, is that all the milk will be consumed 
whatever the time-temperature combination. Practically some milk can end up not being consumed due to spoilage at certain time-temperature combinations thereby reducing the risk.

Exposure concentration of STEC in PDBM per-serving was dependent on the estimated concentration of STEC at PD outlets. Raw PDBM had higher concentrations of STEC persevering than pasteurized PDBM for both age groups. Notwithstanding that children $0-5$ years may consume smaller portions/volumes of milk than the age group above 5, the probability of illness and number of HUS cases were higher in children under 5, based on the frequency of consumption. Furthermore, Signorini and Tarabla (52) reported that children under 5 have an increased probability of severe disease outcomes such as HUS and death following STEC infection. However, it is noteworthy that lower concentrations of STEC in milk can also cause, inter alia, watery and bloody diarrhoea and intestinal discomfort. The probability of illness for both age groups consuming PDBM were extremely small (far less than 1) but this is difficult to validate given the uncertainty which underlie the number of PDBM milk consumers. There are no official reports on HUS cases in SA to benchmark our model outputs. However, in Italy, STEC risk assessment for milk reported similar cases of HUS as reported by the Health Ministry $(20,21)$. Latorre et al. (29) in the US conducted a risk assessment of listeriosis due to consumption of raw milk and also reported a number of listeriosis cases which were in line with reports from the CDC. In our study, for every 100000 PDBM portions per-year, the expected number of HUS cases per-year were 52 and 3.2 for age groups under 5 years and above 5 years, respectively, in raw PDBM and the expected number of HUS cases per-year in pasteurized PDBM were 47 and 2.9 for age groups under 5 years and above 5 years, respectively. Our results differ considerably with those of Grace et al. (24) and Giacometti et al. (21). These disparities in model output can be as a result of the risk model and the data used in each model, for example 
temperature distributions, time distributions as well as prevalence of the pathogen in context (29). Median probability of illness per-serving for STEC in PDBM varied from $9.0 \times 10^{-5}$ to 5.4 $\mathrm{x} 10^{-4}$ for all age groups. The median probability of illness per-serving for STEC in PDBM in this study was very low and within the range of the findings from studies conducted in Europe (16). Given that even low probability of STEC infections could still lead to HUS cases and hospitalization in Europe (16), the same situation can be experienced in SA.

In the current study, the risk of infection and the subsequent development of HUS was most influenced by serving volumes followed by time taken to sell the milk at PD outlets. These factors were the most important in increasing the risk of HUS in both age groups who consume either raw or pasteurized PDBM. Latorre et al. (29) also reported serving volume as a parameter with great influence in the risk of listeriosis in raw milk (correlation coefficient varied from 0.19 to 0.30 for all the scenarios they studied). In the current study, the higher number of HUS cases estimated by the model for children under 5 years, although they consume smaller milk volumes, could be attributed to frequency of consumption (higher in population under 5 years) and infectious dose (lower in children under 5 years). The STEC exposure per-serving was very high in this study for both raw and pasteurized PDBM compared to results in a report by the FDA (2003). This could explain why sensitivity analysis picked serving volume as the most important parameter. Heat treatment of milk greatly reduced the risk of HUS associated with consumption of STEC contaminated milk. Using a linear regression model, Giacometti et al. (20) noted that the number of predicted HUS cases is directly influenced by the probability of heat treatment of milk before consumption and again that consumer behavior is a variable and operational reference point useful to obtain appropriate mitigation measures. Grace et al. (24), Giacometti et al. (21) and Clough et al. (9) reported a zero risk of acquiring HUS in consumers who boil milk 
before consumption and this was also experienced in our study. Escherichia coli is destroyed by temperatures above $63{ }^{\circ} \mathrm{C}$ in fluid milk $(11,35)$. Pasteurization of milk effectively eliminates STEC and other common milk borne pathogens (Listeria monocytogenes, Campylobacter and Salmonella) that could cause severe disease, without causing significant change to nutritional properties in milk (2).

A simulated scenario in this study where milk was stored at $4{ }^{\circ} \mathrm{C}$ throughout the whole PDBM chain, clearly indicated a reduction of HUS risk to consumers by more than $50 \%$, as compared to the current PDBM production and marketing conditions. Producer-distributor bulk milk food chain should enforce handling, transportation and storage between 0 and $4{ }^{\circ} \mathrm{C}$. These temperatures have been known to prevent microbial growth and subsequent risk of high pathogen level at consumption (52). In their risk assessment, Giacometti et al. (21) observed that when farmers did not maintain correct temperatures throughout the supply chain and also due to thermal abuse practices during home transportation and storage, the annual expected cases of HUS infections were higher. We also noted that reduction of time taken to sell milk and consume all the milk at home, significantly reduced the risk of STEC in PDBM. Other studies reported that factors affecting risk of infection by pathogen in milk sold directly to the public include time taken to sell the milk per-day and time taken to consume all the milk at household level $(19,29)$, which is also in accordance with our study. Latorre et al. (29) reported that additional time in milk storage along the food chain increase growth of the pathogen and the subsequent exposure per-serving and risk of illnesses per-serving. We therefore recommend consumption of milk within the shortest possible time just after purchasing, to reduce bacterial growth during inadequate refrigeration which has subsequent consequences of increasing the risk of infection. Studies have proven that $E$. coli cells can grow even at refrigeration temperatures 
(27). Combination of PDBM handling practices (storage at $4^{\circ} \mathrm{C}$ throughout the whole chain + time taken to sell the milk ( $5 \mathrm{~h})+$ time taken to consume the milk (12 h)) along the product chain had more impact in reducing the risk of infection and probability of illness. A quantitative risk assessment study by Njage and Buys (43) revealed that combination of mitigatory interventions, reduces human exposure to hazards contaminating food products. Most WHO guidelines recommend combination of different mitigatory measures in the food value chain to increase food safety (54).

During our analysis, certain model inputs introduce uncertainties. We identified one study (5), apart from our reports $(44,45)$, which provides information regarding the prevalence of STEC in PDBM in SA or in the region. Furthermore, there is no information pertaining quantitative data of STEC and the inherent variability in this parameter in PDBM. In the current study one of the main source of uncertainty was the estimated concentration of STEC in both raw and pasteurized PDBM. We estimated the level of STEC in PDBM based on the method of isolation and quantification that was used in a study by Ntuli et al $(44,45)$. One of the main disadvantage in the method was that, E. coli (STEC) cells are known to enter a dormancy state in the milk, i.e, they are still viable but non-cultrable (18). Therefore, this may have underestimated the quantities of STEC in PDBM, although the cells may still be viable and retain pathogenicity $(3,15)$. Obtaining quantitative data on STEC concentration in PDBM or milk produced and marketed in the same scenario, would enable a more realistic modelling of the PDBM value chain. In other studies, estimated concentrations of STEC in bulk milk ranged from -4.00 Log $\mathrm{CFU} / \mathrm{ml}$ to $-3.5 \mathrm{Log} \mathrm{CFU} / \mathrm{ml}(21,33,46,53)$. However, these were much lower than what we estimated in raw and pasteurized PDBM despite the underestimations. 
The lack of data on cross contamination along the PDBM value chain and the concomitant difficulty in testing the validity of the assumption of no cross contamination is one major limitation of this current study. Storage temperatures at house hold refrigeration was modelled using data obtained from Europe and other western countries, and this might not be a representative of home refrigeration temperatures in SA. Another source of uncertainty and variability in the model was limited data available regarding (i) average volumes of PDBM produced or received at outlets per-day (ii) average volumes of PDBM sold per-day (iii) serving volumes (iv) percentage of consumers who boil milk before consumption (v) frequency of PDBM consumption (vi) the actual population (both children and adults) that consume PDBM in SA. We believe future risk assessment will model this source of variability and uncertainty if appropriate data could be identified. We used a triangular distribution to represent Log reduction counts to represent insufficient heating (33\% of the consumers) and this was adopted from Giacometti et al. (21). The authors reported this as a source of uncertainty in their model as the experimental data on the reduction of STEC counts achieved by insufficient boiling may not be reproduced in home setup, thus, they assumed a triangular distribution. Regarding the set of data we had it was not possible to estimate precisely the absolute risk of HUS in SA in our model. We recommend future risk assessment work to include other vulnerable members of the population, for example the perinatal and the immune compromised.

The study revealed that there is a possibility of HUS cases for consumers of PDBM in SA, considering the STEC concentration in the milk. Information obtained from this current study could help to increase the awareness of potential danger to the health of consumers. For example, the study revealed that failure to maintain a cold chain along the PDBM value chain has significant implications on the risk of STEC infection and development of HUS by 
consumers. Apart from effective pasteurization, effective maintenance of a cold chain has the potential to reduce the risk to consumer even to those who do not boil the milk at household level before consumption. The risk of illnesses can be reduced totally by boiling of the milk before consumption, especially if it is raw.

It is not possible to obtain pathogen-free milk. However, the training on dairy technology, hygiene maintenance and safety for producers and suppliers of PDBM needs to be strengthened to improve public health and safety. The models developed in this study can represent risk assessments for milk produced and marketed in similar scenarios.

\section{ACKNOWLEDGEMENTS}

The authors would like to thank Milk South Africa for funding the project (Pretoria, Republic of South Africa).

\section{REFERENCE}

1. Aijuka, M., G. Charimba, C. J. Hugo, and E. M. Buys. 2014. Characterization of bacterial pathogens in rural and urban irrigation water. J. Water Health. 13:103117.

2. Angulo, F. J., J. T. LeJeune, and P. J. Rajala-Schultz. 2009. Unpasteurized milk: a continued public health threat. Clin. Infect. Dis. 48:93-100. 
3. Boer, E., and A. Heuvelink. 2000. Methods for the detection and isolation of Shiga toxin- producing Escherichia coli. J. Appl. Microbiol. 88.

4. CAC. 1998. Codex Alimentarius Commission, CAC (1998) Principles and guidelines for the conduct of microbiological risk assessment. (Alinorm 99/13A, Appendix II).

5. Caine, L.-A., U. U. Nwodo, A. I. Okoh, R. N. Ndip, and E. Green. 2014. Occurrence of Virulence Genes Associated with Diarrheagenic Escherichia coli Isolated from Raw Cow's Milk from Two Commercial Dairy Farms in the Eastern Cape Province, South Africa. Int. J. Env. Res. Public Health. 11:11950-11963.

6. CDC. 2007. Centers for Disease Control Prevention. 2007. Escherichia coli O157: H7 infection associated with drinking raw milk--Washington and Oregon, November-December 2005. MMWR. Morbidity and mortality weekly report. $56: 165-167$.

7. Claeys, W. L., S. Cardoen, G. Daube, J. De Block, K. Dewettinck, K. Dierick, L. De Zutter, A. Huyghebaert, H. Imberechts, and P. Thiange. 2013. Raw or heated cow milk consumption: review of risks and benefits. Food Control. 31:251-262.

8. Clark, E. M. 2009. Characterization of Escherichia coli of the bovine intestinal tract. In University of Glasgow. PhD Thesis.

9. Clough, H. E., D. Clancy, and N. P. French. 2009. Quantifying exposure to Verocytotoxigenic Escherichia coli $\mathrm{O} 157$ in milk sold as pasteurized: A model-based approach. Int. J. Food Microbiol. 131:95-105. 
10. Crotta, M., F. Paterlini, R. Rizzi, and J. Guitian. 2016. Consumers' behavior in quantitative microbial risk assessment for pathogens in raw milk: Incorporation of the likelihood of consumption as a function of storage time and temperature. $J$. Dairy Sci. 99:1029-1038.

11. D’Aoust, J.-Y., C. Park, R. Szabo, E. Todd, D. Emmons, and R. McKellar. 1988. Thermal inactivation of Campylobacter species, Yersinia enterocolitica, and hemorrhagic Escherichia coli 0157: H7 in fluid milk. J. Dairy Sci. 71:3230-3236.

12. Dean, P., L. Young, S. Quitard, and B. Kenny. 2013. Insights into the pathogenesis of enteropathogenic E. coli using an improved intestinal enterocyte model. PloS one. 8:e55284.

13. Delignette-Muller, M., M. Cornu, and A. S. S. Group. 2008. Quantitative risk assessment for Escherichia coli O157: H7 in frozen ground beef patties consumed by young children in French households. Int. J. Food Microbiol. 128:158-164.

14. Denny, J., M. Bhat, and K. Eckmann. 2008. Outbreak of Escherichia coli O157: H7 associated with raw milk consumption in the Pacific Northwest. Foodborne. Pathog. Dis. 5:321-328.

15. Dinu, L.-D., and S. Bach. 2011. Induction of viable but nonculturable Escherichia coli O157: H7 in the phyllosphere of lettuce: a food safety risk factor. Appl. Environ. Microbiol. 77:8295-8302. 
16. EFSA. 2015. European Food Safety Authority (EFSA). 2015. Scientific Opinion on the public health risks related to the consumption of raw drinking milk. EFSA Journal 13, 3940.

17. FAO/WHO. 2003. Hazard characterization for pathogens in food and water. Available at http://www.who.int/foodsafety/publications/micro/en/pathogen.pdf.

18. Farrokh, C., K. Jordan, F. Auvray, K. Glass, H. Oppegaard, S. Raynaud, D. Thevenot, R. Condron, K. De Reu, and A. Govaris. 2013. Review of Shiga-toxinproducing Escherichia coli (STEC) and their significance in dairy production. Int. J. Food Microbiol. 162:190-212.

19. Giacometti, F., P. Bonilauri, S. Albonetti, S. Amatiste, N. Arrigoni, M. Bianchi, B. Bertasi, S. Bilei, G. Bolzoni, and G. Cascone. 2015. Quantitative risk assessment of human salmonellosis and listeriosis related to the consumption of raw milk in Italy. J. Food Prot. 78:13-21.

20. Giacometti, F., P. Bonilauri, S. Piva, G. Scavia, S. Amatiste, D. Bianchi, M. Losio, S. Bilei, G. Cascone, and D. Comin. 2016. Paediatric HUS Cases Related to the Consumption of Raw Milk Sold by Vending Machines in Italy: Quantitative Risk Assessment Based on Escherichia coli $\mathrm{O} 157$ Official Controls over 7 years. Zoonoses Public Health.

21. Giacometti, F., A. Serraino, P. Bonilauri, F. Ostanello, P. Daminelli, G. Finazzi, M. Losio, G. Marchetti, G. Liuzzo, and R. Zanoni. 2012. Quantitative risk assessment of verocytotoxin-producing Escherichia coli $O 157$ and Campylobacter jejuni 
related to consumption of raw milk in a province in Northern Italy. J. Food Prot. 75:2031-2038.

22. Giacometti, F., A. Serraino, G. Finazzi, P. Daminelli, M. N. Losio, M. Tamba, A. Garigliani, R. Mattioli, R. Riu, and R. G. Zanoni. 2012. Field handling conditions of raw milk sold in vending machines: experimental evaluation of the behaviour of Listeria monocytogenes, Escherichia coli 0157: H7, Salmonella Typhimurium and Campylobacter jejuni. Ital. J. Anim. Sci. 11:e24.

23. Goh, S., C. Newman, M. Knowles, F. Bolton, V. Hollyoak, S. Richards, P. Daley, D. Counter, H. Smith, and N. Keppie. 2002. E. coli O157 phage type 21/28 outbreak in North Cumbria associated with pasteurized milk. Epidemiol. Infect. 129:451-457.

24. Grace, D., A. Omore, T. Randolph, E. KanG'Ethe, G. Nasinyama, and H. Mohammed. 2008. Risk assessment for Escherichia coli O157: H7 in marketed unpasteurized milk in selected East African countries. J. Food Prot. 71:257-263.

25. Hudson, P., and H. Hartwell. 2002. Food safety awareness of older people at home: a pilot study. J. R. Soc. Promot Health. 122:165-169.

26. Iweriebor, B. C., C. J. Iwu, L. C. Obi, U. U. Nwodo, and A. I. Okoh. 2015. Multiple antibiotic resistances among Shiga toxin producing Escherichia coli 0157 in feces of dairy cattle farms in Eastern Cape of South Africa. BMC Microbiol. 15:213. 
27. Kauppi, K., S. Tatini, F. Harrell, and P. Feng. 1996. Influence of substrate and low temperature on growth and survival of verotoxigenic Escherichia coli. Food Microbiol. 13:397-405.

28. Khan, A., S. Das, T. Ramamurthy, A. Sikdar, J. Khanam, S. Yamasaki, Y. Takeda, and G. B. Nair. 2002. Antibiotic resistance, virulence gene, and molecular profiles of Shiga toxin-producing Escherichia coli isolates from diverse sources in Calcutta, India. J. Clin. Microbiol. 40:2009-2015.

29. Latorre, A. A., A. K. Pradhan, J. A. S. Van Kessel, J. S. Karns, K. J. Boor, D. H. Rice, K. J. Mangione, Y. T. Gröhn, and Y. H. Schukken. 2011. Quantitative risk assessment of listeriosis due to consumption of raw milk. J. Food Prot. 74:12681281.

30. Ledenbach, L. H., and R. T. Marshall. 2010. Microbiological spoilage of dairy products.. In, Compendium of the microbiological spoilage of foods and beverages. Food Microbiology and Food Safety. 41-67

31. Loirat, C., M. Noris, and V. Fremeaux-Bacchi. 2008. Complement and the atypical hemolytic uremic syndrome in children. Pediatric nephrology. 23:1957-1972.

32. Marklinder, I., M. Lindblad, L. Eriksson, A. Finnson, and R. Lindqvist. 2004. Home storage temperatures and consumer handling of refrigerated foods in Sweden. J.Food Prot. 67:2570-2577.

33. Marshall, J., T. Soboleva, P. Jamieson, and N. French. 2016. Estimating Bacterial Pathogen Levels in New Zealand Bulk Tank Milk. J. Food Prot. 79:771-780. 
34. Mellmann, A., D. Harmsen, C. A. Cummings, E. B. Zentz, S. R. Leopold, A. Rico, K. Prior, R. Szczepanowski, Y. Ji, and W. Zhang. 2011. Prospective genomic characterization of the German enterohemorrhagic Escherichia coli O104: H4 outbreak by rapid next generation sequencing technology. PloS one. 6:e22751.

35. Mercer, R. G., J. Zheng, R. Garcia-Hernandez, L. Ruan, M. G. Gänzle, and L. M. McMullen. 2015. Genetic determinants of heat resistance in Escherichia coli. Front. Microbiol. 6:932.

36. Msolo, L. 2016. Studies on the prevalence of Escherichia coli O157: H7 in raw milk, milking machines, cattle udder and hand swabs collected from selected dairy farms in the Eastern Cape. In University of Fort Hare. MSc Thesis.

37. Mungai, E. A., C. B. Behravesh, and L. H. Gould. 2015. Increased outbreaks associated with nonpasteurized milk, United States, 2007-2012. Emerging Infect. Dis. 21:119.

38. Nauta, M., and B. Christensen. 2011. The impact of consumer phase models in microbial risk analysis. Risk Anal. 31:255-265.

39. Nauta, M., E. Evers, K. Takumi, and A. Havelaar. 2001. Risk assessment of Shigatoxin producing Escherichia coli $\mathrm{O} 157$ in steak tartare in the Netherlands.

40. Nauta, M. J. 2002. Modelling bacterial growth in quantitative microbiological risk assessment: is it possible? Int. J. Food Microbiol. 73:297-304. 
41. Ndlovu, T., M. Le Roux, W. Khan, and S. Khan. 2015. Co-detection of virulent Escherichia coli genes in surface water sources. PloS one. 10:e116808.

42. Nguyen, Y., and V. Sperandio. 2012. Enterohemorrhagic E. coli (EHEC) pathogenesis. Front Cell Infect Microbiol. 2: 90.

43. Njage, P. M. K., and E. Buys. 2016. Quantitative assessment of human exposure to extended spectrum and AmpC $\beta$-lactamases bearing E. coli in lettuce attributable to irrigation water and subsequent horizontal gene transfer. Int. J. Food Microbiol. 240:141-151.

44. Ntuli, V., P. Njage, and E. Buys. 2016. Characterization of Escherichia coli and other Enterobacteriaceae in producer-distributor bulk milk. J. Dairy Sci. 99:95349549.

45. Ntuli, V., P. M. Njage, and E. M. Buys. 2017. Extended-spectrum $\beta$-lactamase, shigatoxin and haemolysis capacity of $\mathrm{O} 157$ and non-O157 E. coli serotypes from producer-distributor bulk milk. Int. Dairy J. 66:126-134.

46. Perrin, F., F. Tenenhaus- Aziza, V. Michel, S. Miszczycha, N. Bel, and M. Sanaa. 2015. Quantitative Risk Assessment of Hemolytic and Uremic Syndrome Linked to O157: H7 and Non- O157: H7 Shiga- Toxin Producing Escherichia coli Strains in Raw Milk Soft Cheeses. Risk Anal. 35:109-128.

47. Raji, M. A., U. Minga, and R. Machangu. 2006. Current epidemiological status of enterohaemorrhagic Escherichia coli O157: H7 in Africa. Chin. Med. J.119:217. 
48. Robins-Browne, R. M. 2004. Escherichia coli and Community-acquired

Gastroenteritis, Melbourne, Australia-Volume 10, Number 10_-October 2004Emerging Infectious Disease journal-CDC.

49. Ross, T., S. Rasmussen, A. Fazil, G. Paoli, and J. Sumner. 2009. Quantitative risk assessment of Listeria monocytogenes in ready-to-eat meats in Australia. Int. J. Food Microbiol. 131:128-137.

50. SA. 2001 Act (54), (1972). South Africa: Regulations relating to milk and dairy products (Updated).

51. Sanaa, M., L. Coroller, and O. Cerf. 2004. Risk assessment of listeriosis linked to the consumption of two soft cheeses made from raw milk: Camembert of Normandy and Brie of Meaux. Risk Anal. 24:389-399.

52. Signorini, M., and H. Tarabla. 2009. Quantitative risk assessment for verocytotoxigenic Escherichia coli in ground beef hamburgers in Argentina. Int. J. Food Microbiol. 132:153-161.

53. Trevisani, M., R. Mancusi, R. Riu, and A. Serraino. 2013. Quantitative detection of shiga toxin-producing and enteropathogenic Escherichia coli serotypes O157 and O26 in bulk raw milk. Food Anal. Methods. 6:1750-1758.

54. Wilcock, A., M. Pun, J. Khanona, and M. Aung. 2004. Consumer attitudes, knowledge and behaviour: a review of food safety issues. Trends Food Sci. Technol. 15:56-66. 